\title{
Nitric Oxide: Chemistry, Biosynthesis, and Physiological Role
}

Shamsul Hayat, Syed Aiman Hasan, Masaki Mori, Qazi Fariduddin, and Aqil Ahmad

\begin{abstract}
Summary
NO is recognized as a biological messenger in plants. It is a highly reactive gaseous free radical, soluble in water and lipid. It can be synthesized in plants via different enzymatic and nonenzymatic sources such as NOS, NR, XOR, and Ni-NOR. Due to its high lipophilic nature, it can easily diffuse through membrane and can act as a inter- and intracellular messenger and regulate diverse physiological and biochemical processes in plants in a concentration-dependent manner, such as seed dormancy, growth and development, senescence, respiration, photosynthesis, programmed cell death, antioxidant defense system, and so on. Moreover, NO also has an ability to act simultaneously with other molecules and signals in plants. This chapter covers the advances in chemical properties and mechanism of its biosynthesis with special emphasis on the role of NO in the physiological and biochemical changes that occur in plants under normal conditions due to the exogenously applied or endogenously produced NO, along with the cross talk between NO and other phytohormones.
\end{abstract}

\section{1}

\section{Introduction}

Since the past decade, nitric oxide (NO) is recognized as a novel biological messenger in plants and animals and has received special attention from most of the branches of biological sciences, including medicine, biochemistry, physiology, and genetics. The interest of biologists gained special momentum when this highly reactive radical was identified as a potent endogenous vasodilator of the endothelium [1]. Moreover, a widespread biological significance of nitric oxide was first recognized by Koshland [2] who named this free radical as "Molecule of Year." The 1998 Nobel Prize in Physiology and Medicine was awarded for the discovery of NO as a biological mediator produced in mammalian cells. 
The role of NO is not confined only to the animal kingdom, but plants also have the ability to accumulate and metabolize atmospheric NO. Klepper [3] for the first time observed the production of NO in soybean plant, treated with photosynthetic inhibitor herbicides [4, 5], other chemicals [6, 7], or under anaerobic conditions $[6,8]$. In plants, NO can be generated via enzymatic and nonenzymatic pathways. The enzymatic pathway is catalyzed by cytosolic nitrate reductase (cNR), NO synthase (NOS) or NOS-like enzymes, and nitrite:NO reductase (Ni-NOR). Nonenzymatic pathway is nitrite dismutation to $\mathrm{NO}$ and nitrate at acidic $\mathrm{pH}$ values [9-11].

After the discovery of the existence of NO in plant, the question arose, should NO be considered a phytohormone or not because the classical concept of hormone is based on three premises [12]: (i) localized site of biosynthesis, (ii) transport to target cells especially separated from the place of synthesis, and (iii) control of responses through changes in endogenous levels of the chemical. First, NO had been found to be formed mainly in actively growing tissues such as embryonic axes and cotyledons, and the level decreases in mature and senescing organs $[13,14]$. Second, the smaller size of the molecule and its higher diffusion rate through biological membranes mean that NO fits the premise that hormones are easily transported. Third, it is the sensitivity of the target cells, rather than the concentration of the plant hormone, that defines the magnitude of a response [15]; because of this concept, some scientists decided to substitute the term hormone with a wider term, "plant growth regulator." Later on, Beligni and Lamattina [16] categorized NO as a nontraditional regulator of plant growth.

Further investigations led to the finding that $\mathrm{NO}$ is soluble in water and lipid. It can exist in three interchangeable forms: the radical $\left(\mathrm{NO}^{\circ}\right)$, nitrosonium cation $\left(\mathrm{NO}^{+}\right)$, and nitroxyl anion $\left(\mathrm{NO}^{-}\right)$. Due to its high lipophilic nature, $\mathrm{NO}$ may diffuse through membranes [17] and acts as an inter- and intracellular messenger in many physiological functions. It plays a significant role in plant growth and development, seed germination, flowering, ripening, and senescence of organs [18]. Moreover, like other phytohormones, NO also acts in a concentration-dependent manner.

Research on NO in plants has gained a considerable attention in recent years and there is increasing evidence corroborating the role of this molecule in plants. Therefore, in this chapter, an effort has been made to cover the recent advances in chemical properties and mechanism of its biosynthesis with special emphasis on the role of NO in physiological and biochemical changes that occur in plants under normal conditions due to the exogenously applied or endogenously produced NO, along with the cross talk between NO and other phytohormones.

\section{2}

\section{Nitric Oxide Chemistry}

Nitric oxide is a gaseous free radical; its chemistry implicates an interplay between the three redox-related species: nitric oxide radical (NO$\left.{ }^{\circ}\right)$, nitrosonium cation $\left(\mathrm{NO}^{+}\right)$, and nitroxyl anion $\left(\mathrm{NO}^{-}\right)$. In biological systems, $\mathrm{NO}^{\bullet}$ reacts rapidly with atmospheric 
oxygen $\left(\mathrm{O}_{2}\right)$, superoxide anion $\left(\mathrm{O}_{2}{ }^{\cdot-}\right)$, and transition metals. The reaction of NO${ }^{\bullet}$ with $\mathrm{O}_{2}$ results in the generation of $\mathrm{NO}_{x}$ compounds (including $\mathrm{NO}_{2}{ }^{\bullet}, \mathrm{N}_{2} \mathrm{O}_{3}$, and $\mathrm{N}_{2} \mathrm{O}_{4}$ ), which can either react with cellular amines and thiols or simply hydrolyze to form the end metabolites nitrite $\left(\mathrm{NO}_{2}{ }^{-}\right)$and nitrate $\left(\mathrm{NO}_{3}{ }^{-}\right)[19]$. The reaction of $\mathrm{NO}^{\bullet}$ with $\mathrm{O}_{2}{ }^{-}$ yields peroxynitrite $\left(\mathrm{ONOO}^{-}\right)$, a powerful oxidant that mediates cellular injury. At physiological $\mathrm{pH}, \mathrm{ONOO}^{-}$equilibrates rapidly with pernitrous acid $(\mathrm{ONOOH})$ that, depending on its conformation, rapidly decomposes to $\mathrm{NO}_{3}{ }^{-}$or to the highly reactive hydroxyl radical $\mathrm{HO}^{\bullet}$. NO ${ }^{\bullet}$ also forms complexes with transition metals found in heme- or cluster-containing proteins, thus forming iron-nitrosyl complexes. This process alters the structure and function of the target proteins, as exemplified by the activation of soluble guanylate cyclase and the inhibition of aconitases.

In addition, $\mathrm{NO}^{\bullet}$ is extremely susceptible to both oxidation and reduction. Oneelectron oxidation of $\mathrm{NO}^{\bullet}$ leads to the formation of $\mathrm{NO}^{+}$(nitrosonium cation), while the product of one-electron reduction of $\mathrm{NO}^{\bullet}$ is a nitroxyl anion $\left(\mathrm{NO}^{-}\right)$[20-22]. This oxidation can be supported by $\mathrm{Fe}(\mathrm{III})$-containing metalloproteins $[20,21]$. $\mathrm{NO}^{+}$ mediates electrophilic attack on reactive sulfur, oxygen, nitrogen, and aromatic carbon centers, with thiols being the most reactive groups. This chemical process is referred to as nitrosation. Nitrosation of sulfhydryl (S-nitrosation) centers of many enzymes or proteins has been described and the resulting chemical modification affects the activity in many cases. Such modifications are reversible and protein $S$-nitrosation-denitrosation could represent an important mechanism for regulating signal transduction. One-electron reduction of $\mathrm{NO}^{\bullet}$ generates $\mathrm{NO}^{-}$. The physiological significance of $\mathrm{NO}^{-}$has not been clarified. Some workers [20, 23] suggest that it could act as a stabilized form of NO. $\mathrm{NO}^{-}$is also believed to react with $\mathrm{Fe}$ (III) heme and to mediate sulfhydryl oxidation of target proteins.

\section{3}

\section{Biosynthesis of Nitric Oxide}

In biological systems, NO can be formed both enzymatically and nonenzymatically. The enzyme responsible for NO generation in animals is nitric oxide synthase. Although NOS-like activity has been detected widely in plants, animal-type NOS is still elusive. Recently, in pea seedlings, using the chemiluminescence assay, Corpas et al. [24] showed arginine-dependent NOS activity, which was constitutive, sensitive to an irreversible inhibitor of animal NOS, and dependent on the plant organ and its developmental stage.

A gene encoding NOS-like protein AtNOS1 was isolated from the Arabidopsis genome; it is involved in the process of growth and hormonal signaling [25]. It was also observed that AtNOS1 may function as NO source in the process of flowering control [26] and in defense response, induced by a lipopolysaccharide [27]. DNA sequencing analyses did not show affinity of AtNOS1 protein to any of animal-origin NOS isoforms. However, the most recent studies have raised critical questions regarding the nature of AtNOS1 [28, 29]. AtNOS1 (Q664P9) and the orthologous genes from rice (Q6YPG5) and maize (AY110367) have been cloned; however, after 
purification of recombinant protein, no NOS activity has been detected [28]. Moreover, AtNOS1 was identified as a member of GTP-binding family. On the basis of a report by Morimoto et al. [30], in which bacterial protein Yqett, an orthologue of AtNOS1, is defined as GTPase, it has been suggested that AtNOS1 might serve as GTPase, involved in mitochondrial ribosome biogenesis and/or processes of translation [28], and in this case, it might indirectly affect NO synthesis. Later on, it was proposed that the AtNOS1 gene be renamed as AtNOA1 - nitric oxide associated 1 [29]. Although the nature of AtNOA1 remains elusive and controversial [28, 29], there is no doubt that the identification of AtNOA1 protein and the Atnoa1 mutant has provided an effective way to genetically control in vivo NOS activity and the endogenous NO levels as the Atnoa1 mutant has been consistently shown to have impaired in vivo NOS activity and reduced endogenous NO levels [25-27].

Nitric oxide can also be produced by other enzymes, apart from NOS, such as NR. NO generation via NR was demonstrated in vitro [31] and in vivo [32]. NR synthesized this molecule from $\mathrm{NO}_{2}{ }^{-}$, by the participation of $\mathrm{NAD}(\mathrm{P}) \mathrm{H}$ [33]. Transformation of $\mathrm{NO}_{2}{ }^{-}$to NO occurs most probably on a molybdenum cofactor. This synthesis strictly depended on nitrite and nitrate content in the tissue [32, 34, 35]. At a high in vitro nitrite concentration (e.g., $100 \mu \mathrm{M}$ ), NO synthesis constituted approximately $1 \%$ of the total NR reduction activity, whereas in vivo NO generation was estimated at $0.01-0.1 \%$ of the NR activity [32]. NO immediately reacts with $\mathrm{O}_{2}{ }^{--}$, forming peroxynitrite that contributes to a decrease in assayed NO concentration. Taking into consideration $\mathrm{NO}$ loss by the value of $\mathrm{NO}$ reaction with $\mathrm{O}_{2}{ }^{--}$, it was shown that the production of this signaling molecule in leaves of vetch, Chinese rose, and Arabidopsis thaliana is almost 20 times higher than that assayed previously [36]. NO production, depending on NR activity, was also recorded in many other plant species, for example, in cucumber [37], sunflower, spinach, maize [32], Arabidopsis [38], wheat, orchid, aloe [39], and tobacco [40, 41] as well as in Chlamydomonas reinhardtii [42].

Xanthine oxidoreductase (XOR) is another Moco-containing enzyme that has been found to produce NO in plants as well as in animals. Xanthine oxidoreductase occurs in two interconvertible forms: the superoxide producing xanthine oxidase and xanthine dehydrogenase [43]. XOR has been found in pea leaf peroxisomes where the preponderant form of the enzyme is xanthine oxidase and only $30 \%$ is present in the form of xanthine dehydrogenase $[44,45]$. XOR can produce the free radicals $\mathrm{O}_{2}{ }^{--}$and $\mathrm{NO}^{\circ}$ during its catalytic reaction, depending on whether the oxygen tensions are high and low, respectively [46-48]. This property of producing $\mathrm{O}_{2}{ }^{--}$and $\mathrm{NO}^{\bullet}$ radicals confers a key role on XOR as a source of signal molecule in plant cells [49].

Another enzyme that can generate NO from nitrite is a plasma membrane-bound enzyme of tobacco roots (Ni-NOR) [50]. This enzyme has a higher molecular weight than nitrate reductase, but has to be characterized. Other good candidates for enzymatic generation of NO include horseradish peroxides [51], cytochrome P450 [52], catalase, and hemoglobin [53]. The production of NO and citrulline by horseradish peroxidase from $\mathrm{N}$-hydroxy-arginine (NOHA) and $\mathrm{H}_{2} \mathrm{O}_{2}$ was reported a decade ago [52]. More recently, horseradish peroxidase was also demonstrated to 
generate $\mathrm{NO}$ from hydroxyurea and $\mathrm{H}_{2} \mathrm{O}_{2}$ [51]. This source of NO should be carefully considered taking into account that peroxidases are widespread enzymes, involved in important physiological processes of plant cells [54].

Heme proteins that have been proposed as good candidates for the enzymatic generation of NO are cytochromes P450. These proteins are present in plants as well as in animal systems and have been shown to catalyze the oxidation of NOHA by $\mathrm{NADPH}$ and $\mathrm{O}_{2}$ with the generation of $\mathrm{NO}[53,55]$. Hemoglobin and catalase were also reported to produce NO and other nitrogen oxides by catalyzing the oxidation of NOHA by cumyl hydroperoxide [52].

In plants, nitric oxide can also be generated by nonenzymatic mechanisms. Nitrification/denitrification cycle provides $\mathrm{NO}$ as a by-product of $\mathrm{N}_{2} \mathrm{O}$ oxidation into the atmosphere [21]. It is known that the nonenzymatic reduction of nitrite can lead to the formation of $\mathrm{NO}$, and this reaction is favored at acidic $\mathrm{pH}$ when nitrite can dismutate the NO and nitrate [9]. Nitrite can also be chemically reduced by ascorbic acid at pH 3-6 to yield NO and dehydroascorbic acid [56]. This reaction could occur under microlocalized $\mathrm{pH}$ conditions in the chloroplast and apoplastic space where ascorbic acid is known to be present [57]. In barley aleurone layer cells, NO can also be synthesized by the reduction of nitrite by ascorbate at acidic $\mathrm{pH}$ [58]. Another nonenzymatic mechanism proposed for NO formation is the light-mediated reduction of $\mathrm{NO}_{2}$ by carotenoids [59].

\section{4}

\section{Physiological Role of Nitric Oxide}

Nitric oxide has emerged as an important signaling molecule associated with many biochemical and physiological processes in plants [60-62]. NO was classified as a phytohormone that might function as a gaseous endogenous plant growth regulator [63] as well as a nontraditional plant growth regulator [16]. It has the capability to regulate diverse physiological processes in a concentration-dependent manner $[64,65]$, such as root organogenesis, hypocotyl growth, defense responses, stomatal movement, apoptosis, hypersensitive responses, growth and development, and phytoalaxin production [10, 19, 60, 66-72], under different environmental conditions. Therefore, in recent years, the role of NO in regulating various physiological and biochemical activities in plants has become an important area of research. In this section, we only discuss the role of NO in different processes of plants under normal conditions (unstressed plants) because the role of NO in plants under different abiotic and biotic stresses is discussed in other chapters.

\subsection{1}

\section{Effect of Nitric Oxide on Seed Dormancy}

Dormancy prevents seed germination under conditions that would otherwise allow germination. Many endogenous compounds reduce/break seed dormancy, among them are nitrogen-containing compounds that include nitrate, nitrite, hydroxyl- 
1 Nitric Oxide: Chemistry, Biosynthesis, and Physiological Role

amine, azide, and sodium nitroprusside (SNP). The ability of SNP to reduce seed dormancy in lettuce [72], Arabidopsis [73-75], and barley [74] led to the conclusion that NO played some role in seed germination. Moreover, the stimulatory effect of NO on seed germination has also been reported in other crops.

NO stimulated seed germination in Paulonia tomentosa [76] under normal conditions as well as in Suaeda salsa under $\mathrm{NaCl}$ stress [77]. SNP (up to $0.8 \mathrm{mM}$ ) application promoted seed germination in lupin that was more pronounced after 18 and $24 \mathrm{~h}$ and ceased after $48 \mathrm{~h}$ [78]. Similarly in canola, NO stimulated seed germination in a dose-dependent manner: lower concentrations of SNP (0.05$0.5 \mathrm{mM}$ ) enhanced seed germination up to $18 \mathrm{~h}$, whereas high concentrations ( 1 and $2 \mathrm{mM}$ ) inhibited the process [79]. Furthermore, exogenous application of nitric oxide also promoted seed germination in maize [80].

\section{4 .2}

\section{Effect of Nitric Oxide on Growth}

In rapidly growing pea seedlings, treatment of NO showed a dual behavior: lower concentrations (micromolar) increased the rate of leaf expansion, but no beneficial effect was noticed [81] at higher concentrations. Similarly, high concentrations of NO (40-80 ppm) inhibited the growth of tomato whereas low concentrations (0-20 ppm) stimulated the growth of tomato, lettuce [82], and pea seedling [81]. NO also activated the growth of root segments of maize comparable to that by indole acetic acid [65]. Although SNP $(0.1 \mathrm{mM})$ inhibited growth of hypocotyls in potato, lettuce, and Arabidopsis [72], it induced root development in cucumber [60]. Exogenous application of NO inhibited the elongation of mesocotyl in maize seedling [83]. Contrary to this, an increase in the leaf biomass of maize seedlings was observed by the endogenously produced and exogenously applied NO [84]. The effect of NO on plant growth was found to be concentration dependent $[64,65]$. Treating maize seedlings with lower concentration of SNP promoted root growth whereas higher concentration was inhibitory. Seedlings of canola, raised from the seeds treated with lower concentration of SNP, had more root length and dry mass whereas higher concentration reduced the values of these parameters [79]. A similar dual behavior of NO donor SNP was also noted in wheat [85].

\section{4 .3}

\section{Effect of Nitric Oxide on Senescence}

Senescence is a process characterized by water loss and desiccation of plant tissues. Some studies suggest that NO has antisenescence properties. Exogenous application of NO in pea leaves under senescence promoting conditions decreased ethylene level because of the inhibition of ethylene biosynthesis [13, 63, 81]. In Arabidopsis, however, the level of ethylene increased significantly after being exposed to NO gas [71]. It was also observed that NO emission decreased as ethylene production increased from anthesis to senescence [78]. NO donors exert a protective effect against abscisic acid (ABA)-induced senescence of rice leaves by diminishing ABAdependent effects such as leaf senescence, enhanced $\mathrm{H}_{2} \mathrm{O}_{2}$ and malondialdehyde 
(MDA) content, reduction in GSH, ascorbic acid level, and antioxidant enzyme activity [86]. The protective effect was reversed by NO scavenger (PTIO) suggesting that the observed phenomenon may be attributed to NO.

\subsection{4}

\section{Effect of Nitric Oxide on Nitrate Reductase Activity}

Nitrate reductase activity is one of the NO sources in plant roots. Exogenous application of SNP $(100 \mu \mathrm{M})$ significantly enhanced the activity of nitrate reductase in leaves of maize plants [80]; however, in the roots of pea and wheat, SNP did not influence NR activity [87].

\section{4 .5}

\section{Effect of Nitric Oxide on Respiration}

NO affects the mitochondrial functionality in plant cells and reduces total cell respiration due to its inhibitory effect on the cytochrome functioning. In carrot cell suspension, NO reduced total respiration by $50 \%$, and this effect was accompanied by a significant increase in cell death. Similarly, in soybean cotyledon mitochondria, the oxygen uptake was inhibited after NO treatment, but it was restored upon NO depletion [88]. It was concluded that alternative oxidase (AOX) may play a role in NO tolerance in higher plants. Nitric oxide can also modulate other mitochondrial enzymes, tobacco aconitase, which is a constituent of Krebs cycle. Its inactivation by NO decreases the cellular energy metabolism that may result in reduced electron flow through the mitochondrial respiratory electron transport chain and a subsequent decrease in the generation of reactive oxygen species (ROS), the natural byproduct of respiration [89].

\subsection{6}

\section{Effect of Nitric Oxide on Stomatal Movement}

NO has also been reported to play a role in stomatal movement being, together with $\mathrm{H}_{2} \mathrm{O}_{2}$, an indispensable component of ABA-induced stomatal closure [22, 38, 90, 91]. The exogenous application of NO to both monocotyledonous and dicotyledonous epidermal strips induced stomatal closure through a $\mathrm{Ca}^{2+}$-dependent process [92]. In Pisum sativum and Vicia faba plants, abscisic acid increased the endogenous production of NO that was suggested to be the reason for ABA-induced stomatal closure [93]. There are also some convergent evidences that support the involvement of nitrate reductase through the production of NO in guard cells [90] leading to their closure $[90,93]$.

\subsection{7}

\section{Effect of Nitric Oxide on Chlorophyll Content}

NO donors (SNP) have been found to enhance chlorophyll content in potato, lettuce, and Arabidopsis [72]. The role of NO in preserving and increasing chlorophyll content 
in pea and potato [94] was also proved. The protective effect of NO on the chlorophyll retention may reflect $\mathrm{NO}$ effects on iron availability. A strong evidence supporting the role of NO in iron nutrition of plants was presented by Graziano et al. [95] as irondeficient growth conditions normally result in chlorosis. NO treatment increased the chlorophyll content in maize leaves up to the control level [95].

\section{4 .8}

\section{Effect of Nitric Oxide on Photosynthesis}

Photosynthesis is one of the most important physiological processes. The whole metabolism of plants directly or indirectly depends on this process; any change in photosynthetic rate will automatically affect the rest of the processes in plant. However, the role of NO in photosynthesis is poorly understood, which is well indicated by the modest number of invivoand in vitro studies in this area with mixed results [96, 97]. Nitric oxide and its donors such as sodium nitroprusside, $S$-nitroso- $N$-acetylpenicillamine (SNAP), and S-nitrosoglutathione (GSNO) are recognized to differentially regulate the photosynthetic rate. NO gas decreases net photosynthetic rate in Avena sativa and Medicago sativa leaves [98]. NO donor SNP has been found to decrease the level of enzymes that regulate photosynthesis in wheat [99] and in Phaseolus vulgaris [100].

Nitric oxide is able to influence the photosynthetic electron transport chain directly. PS II is an important site for NO action [101]; within PS II complex, important binding sites of $\mathrm{NO}$ are the nonheme iron between $\mathrm{Q}_{\mathrm{A}}$ and $\mathrm{Q}_{\mathrm{B}}$ binding sites [102], $\mathrm{Y}_{\mathrm{D}}$, Tyr residue of D2 protein [103], and manganese (Mn) cluster of water-oxidizing complex [104].

NO donor SNAP does not modify the maximal quantum efficiency $\left(F_{\mathrm{v}} / F_{\mathrm{m}}\right)$ but inhibits the linear electron transport rate and light-induced $\mathrm{pH}$ formation $(\Delta \mathrm{pH})$ across thylakoid membrane, and decreased the rate of ATP synthesis [96]. Another NO donor, sodium nitroprusside, reduces quantum efficiency $\left(F_{\mathrm{v}} / F_{\mathrm{m}}\right)$ in the intact potato leaves but causes no difference in $\Delta \mathrm{pH}$-dependent nonphotochemical quenching (NPQ) [97]. A moderate decrease in $F_{\mathrm{v}} / F_{\mathrm{m}}$ was also observed by SNP treatment in pea leaves [105]. Moreover, NO donor has also been found to slow down the electron transfer between the primary and the secondary quinone electron acceptor in vivo, in a concentration-dependent manner [101, 105, 106].

$S$-Nitrosoglutathione, another NO donor, caused a significant decrease in $F_{\mathrm{v}} / F_{\mathrm{m}}$ value in intact pea leaves and decreased steady-state $\mathrm{qP}$, which indicated that NO increased the proportion of closed PS II reaction center, besides reducing steady-state transient NPQ [101] that resembles reaction center NPG, described by Finazzi et al. [107] in Hordeum vulgare. Wodala et al. [101] suggested different chemical properties of NO donors and different experimental conditions as the reasons to account for the above conflicting results.

\section{4 .9}

\section{Effect of Nitric Oxide on Antioxidant System}

It is now a common belief that $\mathrm{NO}$ acts as a second messenger in plants. One of the most intriguing issues in NO biology is its dual function as a potent oxidant and 
effective antioxidant [108]. This dual role of NO might depend on its concentration as well as on the status of the environment. Oxidative stress is the common result of the action of many environmental factors, manifesting itself in a cell by an increased level of reactive oxygen species [109]. The cytoprotective role of NO is mainly based on its ability to maintain the cellular redox homeostasis and to regulate the level and toxicity of ROS.

The ability of NO to exert a protective function against oxidative stress is caused by the factors such as

(a) reaction with lipid radicals, which stops the propagation of lipid oxidation;

(b) scavenging the superoxide anion and formation of peroxynitrite $\left(\mathrm{ONOO}^{-}\right)$that is toxic for plants but can be neutralized by ascorbate and glutathione;

(c) activation of antioxidant enzymes (SOD, CAT, and POX).

One of the fastest reactions of NO within a biological system is its combination with superoxide anion $\left(\mathrm{O}_{2}{ }^{--}\right)$that leads to the formation of strong oxidant peroxynitrite $\left(\mathrm{ONOO}^{-}\right)[10,19]$ that is one of the major toxic reactive nitrogen species [20] that exerts deleterious effects on DNA, lipids, and proteins [20, 35, 110].

The effect of NO on peroxidase is still scarce and somewhat controvertible; the lower concentration of NO donor SNP increases peroxidase activity in Brassica whereas higher concentration proved inhibitory [79]. Similarly, ascorbate peroxidase activity was inhibited by higher SNP concentration in tobacco and canola [111]. Moreover, higher concentration of SNP inhibited coniferyl alcohol peroxidase activity in Zinnia elegna [112].

Treatment of wheat plant with lower concentration of SNP decreased $\mathrm{H}_{2} \mathrm{O}_{2}$ content, but antioxidant activity was enhanced [85]. Moreover, NO can react with lipid alcoxy ( $\left.\mathrm{LO}^{\circ}\right)$ and peroxyl (LOO ${ }^{\circ}$ ) radicals to stop the propagation of radicalmediated lipid oxidation in a direct fashion $[85,113]$. NO decreased TBARS content in wheat seedlings [85].

\subsection{0}

\section{Effect of Nitric Oxide on Programmed Cell Death}

There are contradictory reports concerning NO and programmed cell death (PCD). The elevated levels of NO were sufficient to induce cell death in Arabidopsis cell suspension, independent of reactive oxygen species [111]. An increase in either NO or ROS individually did not induce cell death, whereas simultaneous increase in NO and ROS activated the process of cell death with typical cytological and biochemical features of PCD [114]. Moreover, the interaction between NO and ROS in PCD induction was also investigated in soybean cell suspension [115], and the researchers concluded that NO by itself does not induce PCD, but the key factor determining it is the NO:superoxide ratio [115]. Contrary to that in Taxus brevifolia and Kalanchoe diagremontiana, SNP caused nitric oxide burst, which led to a significant increase in nuclear DNA fragmentation and cell death [116]. On the other hand, it was suggested that NO donors delay PCD in barley aleurone layers treated with GA, but do not inhibit metabolism in general or the GA-induced 
synthesis and secretion of $\alpha$-amylase. $\alpha$-Amylase secretion is stimulated slightly by NO donor. The effect of NO donors is specific for NO because they can be blocked completely by the NO scavenger 2-(4-carboxyphenyl)-4,4,5,5-tetramethylimidazoline-1-oxyl-3-oxide. Thus, NO may be an endogenous modulator of PCD in barley aleurone cell.

\section{5}

\section{Nitric Oxide and Cross Talk with Classical Plant Hormones}

In this section, we are going to discuss the cross talk between NO and recognized hormones that act simultaneously in different physiological and biochemical processes in plants.

\subsection{1}

\section{Auxins and Nitric Oxide}

NO induced the elongation of maize root segments in a dose-dependent manner [65]. It has, therefore, been proposed that the auxin indole acetic acid (IAA) and NO might share some common steps in the signal transduction pathway because both elicit the same responses in plants. The dependence of auxin on NO in the induction of adventitious root development was recently demonstrated in cucumber explants [60]. Moreover, explants from wood species were also responsive to NO treatment to induce adventitious root formation [117].

In cucumber explants, IAA treatment induces a transient increase in the level of endogenous NO in the basal region of the hypocotyl, where the new meristem develops [60]. This localized NO bulk might stimulate the GC-catalyzed synthesis of cGMP [118]. The GC inhibitor reduced adventitious root formation in both IAAand NO-treated cucumber explants. This effect was, however, reversed when permeable cGMP analogue was added together with GC inhibitor and NO or IAA [60].

Earlier in tobacco, activation of defense genes by NO was also induced by cGMP [68]. These genes may act via cADPR that, in turn, regulates $\mathrm{Ca}^{2+}$ level in plants [119]. Variations in $\left[\mathrm{Ca}^{2+}\right]$ might play a role in the signal transduction pathway leading to the activation of the process of mitotic differentiation to initiate rooting.

Nitric oxide can also act via a cGMP-independent pathway, activating phosphatases and protein kinases including MAPKs. Interestingly, a rapid and transient increase in MAPK activity in response to low level of auxins was reported in Arabidopsis seedling roots [120].

IAA-induced endogenous NO bulk in roots can result in a bifurcated signal transduction pathway in which NO mediates a cGMP-dependent or -independent increase in cytosolic $\mathrm{Ca}^{2+}$, which in turn triggers changes in plant gene expression leading to the auxin response. 


\section{5 .2}

\section{Abscisic Acid and Nitric Oxide}

ABA regulates various vital processes in plants where stomatal movement is one of them. In the guard cell, ABA induces the depolarization of the plasma membrane potential that leads to the generation of a driving force for $\mathrm{K}^{+}$efflux, inactivates $\mathrm{K}^{+}$ influx through inward-rectifying $\mathrm{K}^{+}\left(\mathrm{K}_{\text {in }}^{+}\right)$channels, and activates a current through outward-rectifying $\left(\mathrm{K}_{\text {out }}^{+}\right)$channels. These changes together with both slow and fast activating anion channels facilitate the net loss of salt from the cell [121]. Both cytosolic free $\mathrm{Ca}^{2+}$ concentration $\left(\mathrm{Ca}_{\text {cyt }}^{2+}\right)$ and cytosolic $\mathrm{pH}$ have been reported to participate as second messengers of this response [122]. ABA induces guard cell $\left[\mathrm{Ca}^{2+}\right]_{\text {cyt }}$ elevation either by influx from extracellular space or by release from internal source [123], which leads to the loss of guard cell turgor, favoring stomatal closer.

On the other hand, an exogenous application of NO to both monocotyledonous and dicotyledonous epidermis strips was sufficient to induce stomatal closure through a $\mathrm{Ca}^{2+}$-dependent process [92]. Moreover, it was also reported that in $P$. sativum and V. faba, ABA induces an increase in endogenous NO level. This bulk of ABA-induced NO production was reported to be sufficient and necessary for ABA induction of stomatal closure $[90,124]$. The participation of $\mathrm{NO}$ as a signal molecule in guard cell movement is a very recent topic, and much work is still to be done in this field.

\subsection{3}

\section{Cytokinins, Gibberellins, and Nitric Oxide}

Cytokinins (CKs) stimulate photomorphogenic responses, mainly those related to the de-etiolation and pigment synthesis [125]. In exogenous application, CKs have been reported to inhibit hypocotyl elongation in seedlings grown in the dark [126]. Similarly, NO reduces hypocotyl elongation in Arabidopsis and lettuce seedlings grown in the dark [72]. Moreover, it had also been reported that the CK treatment to cotyledons and leaves grown under dark condition could not cause etiolation to revert completely. However, CK had an ability to abolish the lag phase because in chlorophyll production during subsequent illumination it abolishes the lag phase [127]. On the other hand, NO has also been reported to slightly increase the chlorophyll level in wheat seedlings grown in the dark [72]. Thus, the effect of NO is similar to that of CKs.

As mentioned earlier, CKs regulate the synthesis of some pigments such as anthocyanins and betacyanins. NO plays the same role as CK action on betacyanin accumulation. Moreover, NOS inhibitor and an NO scavenger blocked the action of CKs on betacyanin accumulation [128], suggesting that NO somehow helps CK to promote that response or NO is necessary to accomplish CK function. The first evidence suggesting a direct relationship between CKs and NO production was that the exogenous application of CKs to Arabidopsis, parsley, or tobacco cell cultures leads to a rapid stimulation of NO release [129]. 
$12 \mid 1$ Nitric Oxide: Chemistry, Biosynthesis, and Physiological Role

Some seeds require light for their germination under certain conditions. In such cases, GA has been found to act as an active form of phytochrome [130] to induce germination. However, CK alone is generally ineffective in breaking dormancy, but when it acts synergistically with light or GAs, it allows germination [131]. The germination of lettuce seed (cv. Grand Rapid) is also a phytochrome-dependent process, and it was observed that NO donors are able to stimulate germination in the dark, similar to GA, or under a few minute pulse of white light [72]. However, seeds were also able to germinate in light in the presence of NO scavenger, suggesting that light and NO can stimulate germination in different ways [72]. Moreover, it is yet to be determined whether GA and NO promote germination through the same or different pathways.

\subsection{4}

\section{Ethylene and Nitric Oxide}

Ethylene plays an active role in many plant responses [132]. It was suggested that NO and ethylene caused an antagonistic effect during maturation and senescence of the plant [13]. It was demonstrated that endogenous NO and ethylene content maintain an inverse correlation during the ripening of strawberries and avocados [133] while unripe, green fruits contain high NO and low ethylene concentrations; the maturation process is accompanied by a marked decrease in NO concomitant with an increase in ethylene [133].

\section{References}

1 Schmidt, H.H.H.W. and Walter, U. (1994) Cell, 78, 919-925.

2 Koshland, D.E., Jr. (1992) Science, 258, 1861.

3 Klepper, L.A. (1975) WSSA Abstr., 184, 70.

4 Klepper, L.A. (1978) Plant Physiol., 61 (Suppl.), 65.

5 Klepper, L.A. (1979) Atmos. Environ., 13, 537-542.

6 Klepper, L.A. (1990) Plant Physiol., 93, 26-32.

7 Klepper, L.A. (1991) Pest Biochem. Physiol., 39, 43-48.

8 Klepper, L.A. (1987) Plant Physiol., 85, 96-99.

9 Stohr, C. and Ullrich, W.R. (2002) J. Exp. Bot., 53, 2293-2303.

10 Neill, S.J., Desikan, R., and Hancock, J.T. (2003) New Phytol., 159, 11-35.

11 Graziano, M. and Lamattina, L. (2005) Trends Plant Sci., 10, 4-8.
12 Davies, P.J. (1995) The plant hormone concept: concentration, sensitivity and transport, in Plant Hormones: Physiology, Biochemistry and Molecular Biology (ed. P.J. Davies), Kluwer Academic Press, Dordrecht, The Netherlands, pp. 13-18.

13 Leshem, Y.Y., Wills, R.B.H., and Ku, V.V.V. (1998) Plant Physiol. Biochem., 36, 825-833.

14 Caro, A. and Puntarulo, S. (1999) Free Radic. Res., 31, 205-212.

15 Trewaras, A.J. and Malho, R. (1997) Plant Cell, 9, 1181-1195.

16 Beligni, M.V. and Lamattina, L. (2001) Trends Plant Sci., 6, 508-509.

17 Leshem, Y.Y. (1996) Plant Growth Regul., 18, 155-169.

18 Arasimowicz, M. and Wieczorek, J.F. (2007) Plant Sci., 172, 876-887.

19 Wendehenne, D., Pugin, A., Klessig, D.F., and Durner, J. (2001) Trends Plants Sci., 6, 177-183. 
20 Stamler, J.S., Singel, D.J., and Loscalzo, J. (1992) Science, 258, 1898-1902.

21 Wojtaszek, P. (2000) Phytochemistry, 54, $1-4$.

22 Garcia-Mata, C. and Lamattina, L. (2003) Trends Plant Sci., 8, 20-26.

23 Stamler, J.S. (1994) Cell, 78, 931-936.

24 Corpas, F.J., Barroso, J.B., Carreras, A., Valderrama, R., Palma, J.M., Leon, A.M., Sandalio, L.M., and del Rio, L.A. (2006) Planta, 224, 246-254.

25 Guo, F., Okamoto, M., and Crawford, N.M. (2003) Science, 302, 100-103.

26 He, Y., Tang, R.H., Hao, Y., Stevens, R., Cook, C.W., Ahn, S.M., Jing, L., Yang, Z., Chen, L., Guo, F., Fiovani, F., Jackson, R.B., Crawford, N.M., and Pei, Z.M. (2004) Science, 305, 1968-1971.

27 Zeidler, D., Zahringer, U., Gerber, I., Dubery, I., Hartung, T., Bors, W., Hutzler, P., and Durner, J. (2004) Proc. Natl. Acad. Sci. USA, 101, 15811-15816.

28 Zemojtel, T., Froblich, A., Palmicri, M.C., Kolanczyk, M., Mikula, I., and Wyrwicz, L.S. (2006) Trends Plant Sci., 11, 524-525.

29 Crawford, N.M., Galli, M., Tischner, R., Heimer, Y.M., Okamobo, M., and Mack, A. (2006) Trends Plant Sci., 11, 526-527.

30 Morimoto, T., Loh, P.C., Hirai, T., Asiai, K., Kobayashi, K., Moriya, S., and Ogasawara, N. (2002) Microbiology, 148, 3539-3552.

31 Yamasaki, H. and Sakihama, Y. (2000) FEBS Lett., 468, 89-92.

32 Rockel, P., Strube, F., Rockel, A., Wildt, J., and Kaiser, W.M. (2002) J. Exp. Bot., 53, 1-8.

33 Kaiser, W.M., Weiner, H., Kandlbinder, A., Tsai, C.B., Rockel, P., Sonoda, M., and Planchet, E. (2002) J. Exp. Bot., 53 , 875-882.

34 Kaiser, W.M. and Huber, S.C. (2001) J. Exp. Bot., 52, 1981-1989.

35 Yamasaki, H., Sakihama, Y., and Takahashi, S. (1999) Trends Plant Sci., 4, 128-129.

36 Vanin, A., Svistunenko, D.A., Mikoyan, V.D., Serezhenkov, V.A., Fryer, M.J.,
Baker, N.R., and Cooper, C.E. (2004) J. Biol. Chem., 279, 24100-24107.

37 Dela Haba, P., Aguera, E., Benitez, L., and Maldonado, J.M. (2001) Plant Sci., 16, 231-237.

38 Desikan, R., Griffiths, R., Hancock, J., and Neill, S. (2002) Proc. Natl. Acad. Sci. USA, 99, 16314-16318.

$39 \mathrm{Xu}$, Y.C. and Zhao, B.L. (2003) Plant Physiol. Biochem., 41, 833-838.

40 Planchet, F., Kapuganti, J.G., Sonoda, M., and Kaiser, W.M. (2005) Plant J., 41, 732-743.

41 Planchet, E., Sonoda, M., Zeier, J., and Kaiser, W.M. (2006) Plant Cell Environ., 29, 59-69.

42 Sakihama, Y., Nakamura, S., and Yamasaki, H. (2002) Plant Cell Physiol., 43, 290-297.

43 Palma, J.M., Sandalio, L.M., Corpas, F.J., Romero-Puertas, M.C., McCarthy, I., and del Rio, L.A. (2002) Plant Physiol. Biochem., 40, 521-530.

44 Corpas, F.J., de la Colina, C., SanchezRosevo, F., and del Rio, L.A. (1997) J. Plant Physiol., 151, 246-250.

45 Sandalio, L.M. and del Rio, L.A. (1988) Plant Physiol., 88, 1215-1218.

46 Millar, T.M., Stevens, C.R., Benjamin, N., Eisenthal, R., Harrison, R., and Blacke, D.R. (1998) FEBS Lett., 427, 225-228.

47 Godber, B.L.J., Doel, J.J., Sapkota, G.P., Blake, D.R., Stevens, C.R., Eisenthal, R., and Harrison, R. (2000) J. Biol. Chem., 275, 7757-7763.

48 Harrison, R. (2002) Free Radic. Biol. Med., 33, 774-797.

49 Corpas, F.J., Barroso, J.B., and del Rio, L.A. (2001) Trends Plant Sci., 6, 145-150.

50 Stohr, C., Strule, F., Marx, G., Ullrich, W.R., and Rockel, P. (2001) Planta, 212, 835-841.

51 Huang, X., Von Rad, U., and Durner, J. (2002) Planta, 215, 914-923.

52 Boucher, J.L., Genet, A., Vadon, S., Delaforge, M., Henry, Y., and Mansuy, D. (1992) Biochem. Biophys. Res. Commun., 187, 880-886. 
$14 \mid 1$ Nitric Oxide: Chemistry, Biosynthesis, and Physiological Role

53 Boucher, J.L., Genet, A., Vadon, S., Delaforge, M., Henry, Y., and Mansuy, D. (1992) Biochem. Biophys. Res. Commun., 184, 1158-1164.

54 Veitch, N.C. (2004) Phytochemistry, 65, 249-259.

55 Mansuy, D. and Boucher, J.L. (2002) Drug Metab. Rev., 34, 593-606.

56 Henry, Y.A., Ducastel, B., and Guissani, A. (1997) Nitric Oxide Research from Chemistry to Biology (eds Y.A. Henry, A. Guissani, and B. Ducastel), Landes Company, pp. 15-46.

57 Horemans, N., Foyer, C.H., and Asard, H. (2000) Trends Plant Sci., 5, 263-267.

58 Beligni, M.V., Fath, A., Bethke, P.C., Lamattina, L., and Jones, R.L. (2002) Plant Physiol., 129, 1649-1650.

59 Cooney, R.V., Harwood, P.T., Custer, L., and Franke, A.A. (1994) Environ. Health Perspect., 102, 460-462.

60 Pagnussat, G., Simontachi, M., Puntarulo, S., and Lamattina, L. (2002) Plant Physiol., 129, 954-956.

61 Lamattina, L., Garcia-Mata, C., Graziano, M., and Pagnussat, G. (2003) Annu. Rev. Plant Biol., 54, 109-136.

62 Stohr, C. and Stremlau, S. (2006) J. Exp. Bot., 57, 463-470.

63 Leshem, Y.Y. (2000) Nitric oxide in plants, in Occurrence, Function and Use, Kluwer Academic Publishers, Dordrecht, The Netherlands.

64 Anderson, L. and Mansfield, T.A. (1979) Environ. Pollut., 20, 113-121.

65 Gouvea, C.M.C.P., Souza, J.F., Magalhaes, C.A.N., and Martins, I.J. (1997) Plant Growth Regul., 21, 183-187.

66 Noritake, T., Kawakita, K., and Doke, N. (1996) Plant Cell Physiol., 37, 113-116.

67 Delledonne, M., Xia, Y., Dixon, R.A., and Lamb, C. (1998) Nature, 394, 585-588.

68 Durner, J., Wendehenne, D., and Klessig, F. (1998) Proc. Natl. Acad. Sci. USA, 9, 10328-10333.

69 Kim, O.K., Murakami, A., Nakamura, Y., and Ohigashi, H. (1998) Cancer Lett., 125, 199-207.
70 Durner, J. and Klessig, D.F. (1999) Curr. Opin. Plant Biol., 2, 369-374.

71 Magalhaes, J.R., Monte, D.C., and Durzan, D. (2000) Physiol. Mol. Biol. Plants, 6, 117-127.

72 Beligni, M.V. and Lamattina, L. (2000) Planta, 210, 215-221.

73 Batak, L., Devic, M., Giba, Z., Grubisic, A., Poff, K.L., and Konjevic, R. (2002) Seed Sci. Res., 12, 253-257.

74 Bethke, P.C., Gubler, F., Jacobsen, J.V., and Jones, R.L. (2004) Planta, 219, 847-855.

75 Bethke, P.C., Libourel, I.G.L., and Jones, L.R. (2006) J. Exp. Bot., 57, 517-526.

76 Giba, Z., Grubuisic, D., Todorovic, S. Saje, L., Stojakovic, D., and Konjevic, R. (1998) Plant Growth Regul., 26, 175-181.

77 Li, W.-Q., Liu, X.J., Khan, M.A., and Yamaguchi, S. (2005) J. Plant Res., 118, 207-214.

78 Kopyra, M. and Gwozdz, E.A. (2003) Plant Physiol. Biochem., 41, 1011-1017.

79 Zanardo, D.I.L., Zanardo, F.M.L., Ferrarese, M.D.L.L., Magalhaes, J.R., and Filho, O.F. (2005) Physiol. Mol. Biol. Plants, 11, 81-86.

80 Zhang-Shao, Y., Ren-Xiao, L., and ChengShun, C. (2004) Plant Physiol. Commun., 40, 309-310.

81 Leshem, Y.Y. and Haramaty, E. (1996) J. Plant Physiol., 148, 258-263.

82 Hofton, C.A., Besford, P.T., and Wellburn, A.R. (1996) New Phytol., 133, 495-501.

83 Zhang, M., An, L., Feng, H., Chen, T., Chen, K., Liu, Y., Tang, H., Chang, J., and Wang, X. (2003) Photochem. Photobiol., 77, 219-225.

84 An, L., Liu, Y., Zhang, M., Chen, T., and Wang, X. (2005) J. Plant Physiol., 162, 317-326.

85 Tian, X. and Lei, Y. (2006) Biol. Plant., 50, 775-778.

86 Hung, K.T. and Kao, C.H. (2003) J. Plant Physiol., 160, 871-879.

87 Kolbert, Z., Bartha, B., and Erdei, L. (2005) Acta Biol. Szeg., 49, 13-16. 
88 Millar, A.H. and Day, D.A. (1996) FEBS Lett., 398, 155-158.

89 Navarre, D., Wendenhenne, D., Durner, J., Noad, R., and Klessing, D.F. (2000) Plant Physiol., 122, 573-582.

90 Garcia-Mata, C. and Lamattina, L. (2002) Plant Physiol., 128, 790-792.

91 Desikan, R., Cheung, M.K., Bright, J., Henson, D., Hancock, J.T., and Neill, S.J. (2004) J. Exp. Bot., 55, 205-212.

92 Garcia-Mata, C. and Lamattina, L. (2001) Plant Physiol., 126, 1196-1204.

93 Neill, S.J., Desikan, R., Clarke, A., and Hancock, J.T. (2002) Plant Physiol., 128, 13-16.

94 Leshem, Y.Y., Haramaty, E., Iiuz, D., Malik, D., Sofer, Y., Roitman, L., and Leshem, Y. (1997) Plant Physiol. Biochem., 35, 573-579.

95 Graziano, M., Beligni, M.V., and Lamattina, L. (2002) Plant Physiol., 130, 1852-1859.

96 Takahashi, S. and Yamasaki, H. (2002) FEBS Lett., 512, 145-148.

97 Yang, J.D., Zhao, H.L., Zhang, T.H., and Yun, J.F. (2004) Acta Bot. Sin., 46, 1009-1014.

98 Hill, A.C. and Bennett, J.H. (1970) Atoms Environ., 4, 341-348.

$99 \mathrm{Tu}$, J., Shen, W.B., and Xu, L.L. (2003) Acta Bot. Sin., 45, 1055-1062.

100 Lum, H.K., Lee, C.H., Butt, Y.K.C., and Lo, S.C.L. (2005) Nitric Oxide, 12, 220-230.

101 Wodala, B., Deak, Z., Vass, I., Erdei, L., Altorjay, I., and Horvath, F. (2008) Plant Physiol., 146, 1920-1927.

102 Diner, B.A. and Petrouleas, V. (1990) Biochem. Biophys. Acta, 1015, 141-149.

103 Sanakis, Y., Goussias, C., Mason, R.P., and Petrouleas, V. (1997) Biochemistry, 36, 1411-1417.

104 Schansker, G., Goussias, C., Petrouleas, V., and Rutherford, A.W. (2002) Biochemistry, 41, 3057-3064.

105 Wodala, B. (2006) Acta Physiol. Szeg., 50, 185-188.

106 Petrouleas, V. and Diner, B.A. (1990) Biochem. Biophys. Acta, 1015, 131-140.
107 Finazzi, G., Johnson, G.N., Dall'osto, L., Joliot, P., Wollman, F.A., and Bassi, R. (2004) Proc. Natl. Acad. Sci. USA, 101, 12375-12380.

108 Beligni, M.V. and Lamattina, L. (1999) Trends Plant Sci., 4, 299-300.

109 Mittler, R. (2002) Trends Plant Sci., 7, 405-410.

110 Pryor, W.A. and Squadrito, G.L. (1995) Am. J. Physiol., 268, L699-L700.

111 Clark, D., Durner, J., Navarre, D.A., and Klessig, D.F. (2000) Mol. Plant Microb. Interact., 13, 1380-1384.

112 Ferrer, M.A. and Ros-Barcelo, A. (1999) Plant Cell Environ., 22, 891-897.

113 Lamotte, O., Gould, K., Lecourieux, D., Sequeira-Legrand, A., Lebun-Garcia, A., Durner, J., Pugin, A., and Wendehenne, D. (2004) Plant Physiol., 135, 516-529.

114 de-Pinto, M.C., Tomassi, F., and de Gara, L. (2002) Plant Physiol., 130, 689-708.

115 Delledonne, M., Zeier, J., Marocco, A., and Lamb, C. (2001) Proc. Natl. Acad. Sci. USA, 98, 13454-13459.

116 Pedroso, M.C., Magalhaes, J.R., and Durzan, D. (2000) J. Exp. Bot., 51, 1027-1103.

117 Lamattina, L., Beligni, M.V., Gracia-Mata, C., and Laxalt, A.M. (2001) US Patent $6,242,384$

118 McDonald, L.J. and Murad, F. (1995) Adv. Pharmacol., 34, 263-276.

119 Leckie, C.P., McAisnish, M.R., and Hetherington, A.M. (1998) Plant Physiol., 114, 270-272.

120 Pfeiffer, S., Janistyn, B., Jessner, G., Pichorner, H., and Ebermann, R.E. (1994) Phytochemistry, 36, 259-262.

121 Blatt, M.R. (2000) Annu. Rev. Cell Dev. Biol., 16, 221-241.

122 Blatt, M. and Grabov, A. (1997) Physiol. Plant., 100, 481-490.

123 Schroeder, J.I., Kwak, J.M., and Allen, G.J. (2001) Nature, 410, 327-330.

124 Neill, S.J., Desikan, R., Clarke, A., Hurst, R.D., and Hancock, J.T. (2002) J. Exp. Bot., 53, 1237-1247. 
125 Thomas, T.H., Hare, P.D., and van Staden, J. (1997) Plant Growth Regul., 23, 105-122.

126 Chory, J., Reinecke, D., Sim, S., Washburn, T., and Brenner, M. (1994) Plant Physiol., 104, 339-347.

127 Dei, M. (1982) Physiol. Plant., 64, 153-160.

128 Scherer, G.F.E. and Holk, A. (2000) Plant Growth Regul., 32, 345-350.

129 Tun, N.N., Holk, A., and Scherer, F.E. (2001) FEBS Lett., 509, 174-176.
130 Yang, Y.Y., Nagatani, A., Zhao, Y.J., Kang, B.J., Kendrick, B.E., and Kamiya, Y. (1995) Plant Cell Physiol., 36, 1205-1211.

131 Thomas, T.H. (1984) Plant Growth Regul., 11, 239-248.

132 Abeles, F.B., Morgan, P.W., and Saltveit, M.E. (1992) Ethylene in Plant Biology, Academic Press, San Diego, CA.

133 Leshem, Y.Y. and Pinchasov, Y. (2002) J. Exp. Bot., 51, 1471-1473. 